

\title{
The pragmatic use of vocatives in private one-to-one digital communication
}

\author{
Esther Asprey and Caroline Tagg \\ Birmingham City University | Open University
}

\begin{abstract}
This article examines a corpus of private text messages collected in Birmingham and surrounding towns in 2015. We look specifically at pragmatic roles played by the vocatives we find in the corpus. Since text messages are sent to targeted recipients, vocatives are structurally redundant, and we review literature concerning vocatives in spoken and written data to first see what categories others have proposed for these functions. We then challenge some of these categorisations, identifying a new category of 'focuser' which we argue is akin to a summons in spoken language. We also examine the pragmatic value of vocatives in performing identity work for both sender and receiver. We finish by looking at gendered performance of identity as a case study in our corpus of how text producers construct themselves and others.
\end{abstract}

Keywords: Vocatives, pragmatic function, text messaging, gender, identity, categorisation

\section{Introduction}

This article explores how and why vocatives are used in private, one-to-one digital communication. Vocatives - address terms which refer directly to the addressee of an utterance (McCarthy and O’Keeffe 2003: 153) - are structurally redundant in their summoning and turn taking functions in this context. At the same time, the interpersonal functions of vocatives mean that they may be an important resource for creating and sustaining intimate relationships through digital communication. The corpus of mobile messages used in this study was collected in and around Birmingham as part of a larger research project, Messaging in the Midlands, which aimed to explore the diversity of linguistic resources exploited in mobile messaging. Our analysis reveals a range of vocative forms which are employed across age, gender and language-background categories for various interpersonal functions, including greeting and thanking, as well as mitigating and badinage. Mobile messaging is a short form of communication with expressive constraints and, as we shall argue, texters can use resources like emoticons, emojis, adverbials and vocatives to build identities for themselves and assign identities to others. 
The study makes three contributions to our understanding of vocatives and of internet pragmatics. Firstly, in addition to interpersonal functions, the study identifies a new use of vocatives which we call 'focusing' and which serves to prepare an interlocutor for a message by drawing their attention to it and mitigating the demands being made. This function has parallels with the 'summons' function identified in speech, and thus challenges the assumption that summoning is not a concern in one-to-one digital communication. Secondly, the study draws attention to a somewhat neglected function of vocatives, that of identity positioning. We show that the use of vocatives for creating rapport often involves acts of self-presentation and the positioning of others, and that vocatives in English are relatively easy for all speakers, L1 and otherwise, to deploy for meaning making purposes. Although shaped in this context by the digital affordances available to interlocutors, this finding has implications for our understanding of the function of vocatives in other contexts, including politics and business. Thirdly, we discuss the potentially gendered nature of the aggregate repertoire of users' language. We look closely at the texting practices of men and women and discuss differences and similarities in the language our informants use to see if there are idiolectal practices which could be said to reflect some of the practices which have been loosely linked to gender (cf. Cameron 1995; Eckert 1995; Holmes 2008).

\section{Vocatives and spoken discourse}

Research into the pragmatics of vocatives has, in English at least, been slow to come, with linguists concentrating instead on the structural properties of the construction. The degree to which vocatives are grammaticalised varies between languages, being for example a construction which is case-governed in many Indo-European languages including Irish (O’Rahilly 1921), Polish (Jaworski and Galasiński 2000) Serbian (Hammond 2005), and Scottish Gaelic (Gillies 1993). Astruc-Aguilera (2005: 2) reports that English vocatives can appear clause initially or clause finally and therefore, like other extrasentential elements, they are mobile and, in systemic functional terms, can act as themes. It is in part because of this mobility, she argues, that vocatives can fulfil various communicative functions, including “attracting the addressee's attention or maintaining the communication” (Astruc-Aguilera 2005: 15). As themes, vocatives mark information given and can thus serve as a focuser when they appear initially in a message.

Biber et al. (1999: 1109) show that vocatives can take many forms, and give the following examples: 
- $\quad$ endearments (honey, darling, sweetie pie, dear),

- $\quad$ kinship terms (Daddy),

- familiarisers (guys, dude, bud, bro),

- $\quad$ first name familiarised (Johnny),

- $\quad$ first name full form (John),

- $\quad$ title and surname (Mr. Smith),

- $\quad$ honorific (Sir),

- $\quad$ nickname (Speedy),

- $\quad$ impersonal vocatives (Someone get that phone, will you!)

- $\quad$ and even elaborated nominal structures such as: "those of you who want to bring your pets along.”

These forms emerged from empirical study of a large corpus and find parallels with categories put forward later by Murphy and Farr (2012: 2), who recap the distinction between endearments as "used with intimates, close friends and family members" and familiarisers with "friends of equal status". This definition is problematic, not only because it suggests that these formal labels trespass on the range of the functional, but because evaluating the nature and intimacy of a relationship is a subjective and thus arbitrary matter. In Murphy and Farr's data, it seems that, as in Biber et al. (1999), male usage of the vocative gets coded as familiariser. Discussion of 'boy' in Cork dialogue centres on male use and is coded as familiariser and discussion of 'girl' in wider Hiberno-English usage is coded as endearment. The labelling of forms in this way also neglects consideration of the extent to which forms shift in meaning over time and the fact that its meaning may depend on how the vocative is being used in context, and to whom. Kiesling (2004: 288), for example, reports the rise of dude as a vocative used between intimates (couples in relationships) in a North American context, even though he does make it clear that dude as a vocative usually signals cool camaraderie. According to Biber et al. (1999: 1088), an addressee can potentially be referred to using any of the above forms (gender and age being the only restriction in the case of titles). At the same time, however, they argue that choice of vocative form "provides an index of (projected or assumed) relationship between speaker and addressee” (Biber et al. 1999: 1112). This index is possible precisely because vocative choices are theoretically constrained by social roles and tenor relationships and are thus to some extent indexical of these.

The role played by vocatives in fulfilling relational or interpersonal purposes is widely accepted by researchers (Brown and Ford 1964; Jaworski and Galasiński 2000; Hultgren 2017). 
Drawing on their corpus data, McCarthy and O’Keeffe (2003: 155) identify five discrete functions associated with vocatives. Of these, only two- the use of vocatives as a device to gain the attention of a speaker ('summon') and to control turn-taking ('turn') - relate primarily to addressivity. The other three functions - badinage, mitigating threats to face, and relational talk - highlight the interpersonal function of vocatives. In each case, the vocatives do not necessarily carry out the ascribed function, but are rather seen to occur within the context of these functions (McCarthy and O'Keeffe 2003: 7). The role that vocatives play in relational work is strikingly illustrated by Hultgren's (2017) study which explores their overuse by call centre operators who use them as time efficient strategies for creating rapport with customers; and in Jaworski and Galasiński’s (2000) analysis of how power relations are negotiated by politicians through their selection of address terms.

Less foregrounded across the literature is the role that vocatives may play not only in projecting an assumed relationship, but in performing social identity and in discursively positioning the people involved in the interaction. The concept of positioning - put forward as a way of understanding identity performance by Harré and colleagues in the 1990s (Davies and Harré 1990; Harré and Langenhove 1999) - holds that, rather than moving between predetermined roles, interlocutors constantly (re)position themselves and others as an interaction unfolds, in line with wider beliefs, past experiences, and awareness of social conventions. This interactional or discursive process takes place through the use of various linguistic and communicative resources, including the use of vocatives. The vocative in English is easily deployed for positioning work.

Although not foregrounded, a number of studies point to the role that vocatives can play in identity positioning. Kiesling's (2004) analysis of the vocative dude, in which he charts its shift from an address term used between young men to more general address, shows how the word has come to index a particular stance, characterised by what he terms "cool solidarity", nonchalance and non-conformity. Interestingly, however, the use of dude as an identity resource appears to run alongside its shift from general address term to discourse marker that may have no addressee. In another example, Axelsson (2006) considers the pragmatic role of vocatives in intercultural communication, reporting on use of vocatives in a multicultural group task at a large American university. Her focus is on the vocatives used to address Hideki, a Japanese L1 exchange student, by other members of the group he is working with. Although he wished to contribute fully to the project and on an equal level with his English speaking group members, the use of vocatives by others in the group suggested that they were trying at times to subordinate him whilst bolstering their own positions within the group. In other words, 
vocatives were used both to position Hideki in a particular way and to index the speakers' own social roles as group leaders. Other studies report a similar use of vocatives to index one’s own status and to position others (whilst creating rapport), including Skovholt's (2015) study of a virtual team whose leader addressed her team using creative nicknames, as in "Hi all letterenthusiasts" and "Hi Agendaese”. Her use of these vocatives was part of her attempt to establish her identity as a particular kind of leader. As well as signalling solidarity and group belonging, she also "creates a category that serves to characterize, include and even compliment the receivers” (Skovholt 2015: 109-110). Meanwhile, a study by Jaworski and Galasiński (2000) shows how use of "marked" vocatives in Polish political debate can be used to position opponents and also lead to judgements about the speaker. In the context of a two-person debate, the authors argue, vocatives are redundant in terms of their role in turn organisation. Instead, in this context they are used to build positive self-image and legitimise political positions.

The importance of vocative use for identity claims in political contexts is similarly highlighted by news reports of verbal sparring in the Northern Ireland Assembly (McAdam 2014). The Democratic Unionist MLA [Member of the Legislative Assembly] politician Gregory Campbell was reprimanded for replying to a Sinn Féin MLA in "Mock Irish” (cf. Mock Spanish, Hill 1995, 1998). He parodied the formulaic response given to the Speaker by Sinn Féin MLAs, 'Go raibh maith agat, a Phríomh-Leas Ceann Comhairle' (Thank you, Speaker) by rendering it as "curry my yoghurt can coca coal-yer”. This changing of the utterance to closely resemble a menu order plays with meaning and context to successfully ridicule the Sinn Féin MLAs’ identity by proxy, attacking the language they choose to use.

\section{Vocatives and digital communication}

A key argument in the literature regards the need to explore vocatives in context and to acknowledge the fact that their pragmatic use and social function will be influenced by various situational variables (Brown and Ford 1964): for example, the overuse of first names reported by Hultgren (2017) was motivated by contextual constraints, namely the requirement for call centre operators to perform interpersonal work whilst completing calls quickly. Little has been written about the uses and functions of vocatives in the context of digitally mediated communication. However, they receive some mention in studies exploring addressivity and audience design on social media (Frobenius 2013; Tagg and Seargeant 2014). In multiparty, public online contexts, vocatives can serve as one linguistic strategy or resource available to users in targeting and addressing certain individuals, and excluding others. Drawing on 
Goffman (1975) and on Bell’s (1984) ‘audience design’ framework in their study of Facebook newsfeeds, for example, Tagg and Seargeant (2014) find that users exploited vocatives and post- and photo-tagging as explicit addressivity strategies alongside a range of other more implicit means, including language, dialect and script choice; dividing messages into separate posts; and vague language and contextualised references. The importance of addressivity to public multiparty contexts can be evidenced by the development of @, which emerged from user practices on Twitter (Zappavigna 2012: 3).

The significance of vocatives as an addressivity strategy in such contexts lies to some extent in the large, diverse, and invisible audiences faced by users on social network sites characterised by 'context collapse' (boyd and Marwick 2011) - that is, where people a user knows from various offline contexts (friends, colleagues, parents, acquaintances) are brought together into one online space. Users cannot know exactly who from amongst their Friends will notice their posts, and so addressivity strategies are important in drawing particular people's attention and also indicating who a post is not intended for. This is a process which Marwick and boyd (2014) call 'social steganography', or hiding in plain sight: anyone can read the post, but only a targeted few may access its full meaning. In such contexts, vocatives serve a kind of summoning function - indicating the intended addressee given the potentially large and diverse audience for each post. This is not a function that would appear to be relevant to private, one-to-one online communication.

The potential significance of vocatives in social media can also be explained by online users' reliance on text-based cues. In face-to-face conversations, speakers can assign audience roles using resources including "physical arrangement, conversational history, gestures, manner of speaking, and linguistic content” (Clark and Carlson 1982: 346), many of which are not available in most virtual communication. As Georgakopoulou (1997) points out in her study of email, given the usual lack of paralinguistic cues associated with face-to-face spoken conversation, textual cues (such as vocatives) have to take on the burden of pragmatic work, and are therefore likely to be significant in social meaning-making.

\section{Affordances and constraints of digital communication and the mobile phone}

Although the research literature focuses overwhelmingly on SMS, initial research into the messaging app WhatsApp suggests that users perceive it as more conversational and immediate. This is due in part to its affordances (e.g., that information is provided as to whether 
an interlocutor has seen your message) which, as well as perceptions of cost, encourage users to produce quicker, shorter turns (Church and de Oliveira 2013). Use of WhatsApp, like Facebook Messenger, relies on a user having a roaming internet connection, which it is not clear that all users interviewed in the present study did. It is however clear that the multimedia affordances of WhatsApp are greater than traditional SMS allows. Unlike both Facebook Messenger and SMS, WhatsApp allows users to search for topical meme jpegs via use of the plugin Giphy (Wollaston 2017) and this may add to the ludic possibilities and communicative opportunities for WhatsApp users, since the latter offers more topical possibilities for images. Finally, both Facebook Messenger and WhatsApp allow for group communication, but the nature of our study meant that participants rarely selected messages from larger group messages to show to us, and so this affordance cannot be investigated further here.

In contrast to semi-public sites like Facebook, vocatives would seem to be redundant in their summoning or turn-taking functions in private exchanges via SMS or any of the mobile messaging apps discussed above (which we refer to collectively as 'mobile messaging'). With few exceptions (explained in the methods section below), the messages we collected were sent from one person to one other person - what Herring (2007) calls a 'one-to-one' participation structure. In this context, the arrival of the message itself (accompanied in some cases by an alert) acts as the 'summons', in much the same way as a telephone ring (Schegloff 1993, 2002) and the message itself usually provides information about the sender. These contextual factors would seem to intersect with others to create a situation in which vocatives are used not for addressivity purposes but as an interpersonal strategy for maintaining relationships and as an important resource in processes of identification.

Messaging apps make possible the immediate, synchronous exchange of messages via the private space of an individual's mobile phone, and are therefore often exploited for personal communication between people who know each other well (Katz and Aakhus 2002; Madianou and Miller 2012). Despite the expectation in some contexts for immediate replies (Laursen 2005), messages are generally seen as less intrusive than phone calls (Darics 2014), and they are preferred by users for their privacy (Rettie 2007). Messaging also facilitates constant communication, with families and friends often performing frequent 'check-ins' during the day (Rainie and Wellman 2012). Where mobile messaging is used as an ongoing channel of communication, there is no need to start and open conversations in the way that telephone or face-to-face conversations require (often, as Sacks and Schegloff (1973) detail, necessitating long opening and closing sequences). 
Given the virtual nature of digital interactions, interlocutors must draw on linguistic and discursive strategies to co-construct a shared communicative space (Lyons 2014). This means that intimacy is reflected in, and also created by, a particular use of language, characterised by a high frequency of non-standard spellings and in-group acronyms as well as a high use of pronouns - particularly the second person pronoun you - vague language, emoticons, kisses and formulaic expressions such as $c$ u later and have a good time (Tagg 2012). Online interactants must also construct social identities through graphological means - in boyd's (2001) words, to write themselves into being. Online processes of (dis)identification have more recently been portrayed as complex reflections or extensions of people’s wider identity projects (Leppänen et al. 2014; Leppänen, Westinen and Kytölä 2017).

Interestingly, however, the need for graphological markers to carry a large burden of relational and identification work potentially conflicts with the communicative demand for brevity, which arises not only from the physical constraints of the medium but also social expectations around prompt replies (Thurlow and Brown 2003). The need for brevity encourages the use of abbreviations, which have subsequently taken on social meaning, as well as the use of other 'shortcuts' to achieving intimacy, including metonyms (Littlemore and Tagg 2018) and emoji (Danesi 2017), both of which constitute space-saving strategies in fulfilling interpersonal functions. One feature that has not been explored in any depth in the existing literature is vocatives, perhaps in part because of ethical issues and anonymization practices. Yet there are various reasons for assuming that vocatives might have a particularly important role to play in signalling intimacy and maintaining close relationships in digital communication, namely their efficiency as an interpersonal resource: the fact that they are at once very brief as well as relatively invariant and yet highly individualised (Hultgren 2017).

\section{Context, data and methods}

\subsection{Description of context}

In this study of the pragmatics of vocatives, we draw on mobile messaging data collected as part of a six-month project, Messaging in the Midlands, ${ }^{1}$ that aimed to explore the varied

\footnotetext{
${ }^{11}$ Messaging in the Midlands (PI: Author 2; CI: Author 1, RAs: Alice Powers, Leonie Brueggeman, Ashley Marvell), 2015, funded by the Institute for Research into Superdiversity
} 
linguistic resources appropriated by individuals living in the ethnically diverse West Midlands of the UK. An overview of our methods and findings can be found in Tagg and Asprey (2017). Based on existing research, we had not expected vocatives to feature prominently across the data, but they emerged as potentially socially salient during data analysis. Although our dataset is relatively small, its advantage lies in the broad range of contributors, enabling us to reach conclusions that reflect the practices of West Midlanders of different genders, ages, language backgrounds, and professions.

Research was conducted in March-September 2015 in the Library of Birmingham, the University of Birmingham, a local library in the satellite suburb of Rubery to the south-east of Birmingham, and in Walsall FE College in the town of Walsall to the north. Rubery and Walsall were chosen as data-collection sites alongside Birmingham in an attempt to explore how the effects of shifting and increasingly complex migration patterns might stretch beyond large cities and into traditionally less ethnically diverse neighbourhoods. Birmingham is in many respects an acknowledged site of linguistic 'superdiversity' (Creese and Blackledge 2010). Walsall and Rubery exhibit the traits characteristic of superdiverse locations but, crucially, do so in an uneven way, so that certain electoral wards in these places might well exhibit high levels of diversity while others might exhibit very low levels. For example, the 2011 census for Walsall (Walsall MBC online) reveals just 3\% of ethnic minority residents for Pelsall ward, 5.5\% for Bloxwich East and 11.3\% for Rushall, Shelfield, In contrast, St Matthew's ethnic minority population was $46.9 \%$ and Pleck's 58.9\%. The demographic details of our participants are included in Table 1.

Table 1. Demographic details of our participants

\begin{tabular}{|l|l|}
\hline Gender & Females: 33 (259 messages) \\
& Males: 26 (144 messages) \\
\hline Age & $56-65$ (1950-1959): 17 messages \\
& $46-55$ (1960-1969): 31 messages \\
& $36-45$ (1970-1979): 56 messages \\
& $26-35$ (1980-1989): 62 messages \\
& $16-25$ (1990-1999): 216 messages \\
\hline
\end{tabular}

(IRiS), University of Birmingham

(http://www.birmingham.ac.uk/research/activity/superdiversity-institute/index.aspx). 


\begin{tabular}{|c|c|}
\hline Place of birth & $\begin{array}{l}\text { Birmingham (n=22) } \\
\text { Cannock } \\
\text { Stourbridge } \\
\text { Walsall } \\
\text { Wolverhampton } \\
\text { London } \\
\text { Leicester } \\
\text { Manchester } \\
\text { Milton Keynes } \\
\text { Oxford } \\
\text { Somerset } \\
\text { Scotland } \\
\text { China (n=3), } \\
\text { Congo (Brazzaville) } \\
\text { Eritrea } \\
\text { Germany } \\
\text { Netherlands } \\
\text { Sweden } \\
\text { Syria } \\
\text { Uganda } \\
\text { United Arab Emirates } \\
\text { Vietnam }\end{array}$ \\
\hline Languages spoken & $\begin{array}{l}\text { English, British Sign Language, Punjabi, Urdu, Mirpuri, Sylheti, Bengali, Hindi, } \\
\text { Arabic, Farsi, Spanish, French, Dutch, German, Czech, Polish, Italian, Swedish, } \\
\text { Somali, Congolese, Tigre, Kikongo, Swahili, Luganda, Irish Gaelic, Welsh, } \\
\text { Patwa, Mandarin, Kurdish, Hebrew, Japanese, and Cantonese. }\end{array}$ \\
\hline Apps/platforms used & SMS, WhatsApp, and Facebook Messenger \\
\hline
\end{tabular}

\subsection{Methods}

We set up stalls at each venue and waited for interested parties to approach us and volunteer to be interviewed. Each stall had two posters, clear information about the project, sweets and a prize to draw in people who might wish to take part. This approach proved successful, although success varied from site to site and across the sample population. The main drawback was the fact that, although our intention was to collect dyadic message information from pairs of intimates, in practice we found that most individuals approached us by themselves. Once participants had approached the stall and chatted to us, we informed them of the nature of the project. If they were happy to take part, they completed a questionnaire with their age, gender, 
place of origin, current place of residence and any other places of residence. We also asked them which languages they could speak and/or write, and gave a binary choice of "a little” and “a lot” for proficiency. The informants were also asked which phone model they currently used and which messaging platforms they used. We recognise the limitations of questionnaires in eliciting valid data, particularly those using closed questions which may not include the exact answer that participants would ideally give, and sought to offset the disadvantages to some extent by engaging the participants in informal talk around their responses.

Informants were also asked to submit securely and anonymously up to ten messages which they felt represented stylistic variation in their texting. They were asked to describe how they felt their texting style varied according to interlocutor. Informants proved remarkably able to express register variation when describing their text style to us. All participants were given a statement of informed consent allowing them the right to withdraw in compliance with the UK Data Protection Act (1998). Despite many people's reassurances that their interlocutors would not mind, we have not used any messages sent by people who were not present to give consent. This has limited our ability to explore the co-construction of meaning across turns, a limitation we aim to overcome in subsequent research.

\subsection{Data and analysis}

We surveyed 59 participants and collected a corpus of 412 messages (4371 words) sent through SMS, WhatsApp, and Facebook Messenger. Only one participant contributed messages that were sent to a group, rather than an individual $(n=8)$. The screen-snaps were anonymised and transcribed into an Excel database, together with relevant meta-data. Each message was linked to its sender and thus to the sender's biographical details held in a linked table. These biographical details had been transcribed from the questionnaire into Excel, and enabled us to sort and filter the message data according to age, gender, place of birth, phone type, and so on.

We draw on quantitative methods to interrogate our interactional data alongside analysis of a participant survey and qualitative analysis of selected exchanges. The quantitative data analysis was conducted in Excel. We identified features of interest by drawing on the existing literature (Tagg 2012) and by allowing interesting features to emerge from the data. We worked with 23 categories, including respellings, discourse markers, slang, and language mixing, greetings, sign-offs, emoji, kisses, and dialect representation. Messages were tagged in Excel according to which of these features they contained. It was thus possible to identify the features used by a particular social group or individual or in a particular message type. We carried out 
analyses as to the distribution of the above features across gender and age group, which we draw on below in the qualitative analysis of vocatives.

When vocatives emerged from this analysis as socially salient, we further analysed them in terms of form, function, and position, across the whole corpus and for each gender, drawing on the literature into vocatives in spoken discourse. This enabled us to explore differences between spoken and digital vocatives. The Excel datasheet also enabled us to analyse the extent to which vocatives occurred alongside the other features of analysis mentioned above. We then analysed the exchanges more qualitatively, eventually selecting two exchanges for which we had access to both interlocutors' data in order to explore the role these vocatives play in people’s relational and identification work via mobile messaging.

It was not always possible to categorise the vocative forms and functions. In three cases we could not determine whether the use of bro or bruv was being used as a familiariser or as a kinship term. This was a weakness of our data collection methods, because we were unsure as to whether the message sender was writing to their brother. However, it also serves as a useful reminder of the shifting meaning of vocatives, and the need to take contextual features into account when assigning forms to categories. It points to the notion that formal labels and their functions may not hold constant across time or across social groups.

\section{Findings: first names and focusing}

We identified 57 vocatives across the 412 messages (4371 words). In only one instance did two vocatives occur in the same message, meaning that $13.6 \%$ of messages contained a vocative. Vocatives were used by around half of the 59 participants $(n=29)$, suggesting that some people may be using them more regularly than others (of the 29 users, 12 used between two and five vocatives in the data they submitted, with the others using just one). They were used by both men and women to a similar extent, although men were slightly more likely to use them and they often chose different vocative forms and used them for different purposes: in short, men were more likely to use familiarisers, while women were more likely to use endearments and first name familiarised; and men were more likely to use vocatives in badinage and greetings, while women were more likely to use them in mitigations, heightening intimacy and 'focusing' (described below). Vocatives were also used across age groups, with younger people (aged 1625) tending to use more familiarisers and endearments than older groups (who were more likely to use first names) but in general using fewer vocatives than the other groups (those aged 46- 
55 were the heaviest users by a small margin). However, it is worth noting that numbers are very low once we start comparing male and female usage and breaking down the data by age.

It is also worth noting that the locations people are based in and the age and gender groupings of our speakers, together with their ethnic origins, were not subject to quotas and cannot therefore be compared systematically for demographic analysis. Nevertheless, such controlling is something which would be desirable for future avenues of research, and we look here only at such demographic trends as can be robustly supported with evidence.

While these figures show that vocatives are far from compulsory in mobile messaging, neither should they be considered unusual. This is perhaps surprising given that a mobile message is usually directed at one person, thus rendering vocatives structurally unnecessary. Below, we start with an overview of their form, function and position which reveals a surprisingly high use of first names as well as the use of vocatives in mobile messaging for both focusing the receiver's attention and softening the apparent demand made of the receiver for an immediate reply.

The vocative forms used across the corpus (see Table 2) range from proper nouns through endearments to slang terms in British English associated with young people (such as fam and bro -shortened forms of family and brother, respectively). Interestingly, although numbers are too low for conclusive statements, we found that most familiarisers were used by men (5 of 6) and most endearments by women (11 of 12), while only women used first name familiarised. Note that the two uses of everyone (classified as 'impersonal') occurred in two of the eight group messages sent by one participant (all other messages represented one-to-one communication).

Table 2. Distribution of vocative forms

\begin{tabular}{|c|c|c|}
\hline Form & No. & Example \\
\hline First name full form & 22 & $\begin{array}{l}\text { Hi } \underline{\mathbf{F 1}} \text {, I'm running a bit late! Should be back in about } 20 \text { minutes. } \\
\text { N1 }\end{array}$ \\
\hline First name familiarised & 6 & 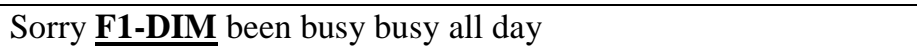 \\
\hline First name + honorific & 1 & $\begin{array}{l}<\text { emoji }>\text { monkey }</ \text { emoji }>\text { OTHER SCRIPT-JAP [Hey, } \underline{\text { NAME }} \\
\text { san, how are you today?] }\end{array}$ \\
\hline Nickname & 1 & $\begin{array}{l}\text { Hello F1-NICK by the mailbox getting off mometarly I will head } \\
\text { to library properly be in there depending where you are upon } \\
\text { arrival take it easy in your own time } \\
<\text { emoji> winkingface</emoji> }\end{array}$ \\
\hline
\end{tabular}




\begin{tabular}{|c|c|c|}
\hline Endearment & 12 & $\begin{array}{l}\text { Morning gorgeous. Whatsapp from your bro if you get a chance. } \\
\text { I love you baby xxx }\end{array}$ \\
\hline Familiariser & 7 & Thanks mate it didn't cost me a penny lol $\mathrm{x}$ \\
\hline Kinship term & 2 & Awwww mom x you don't need to $\mathrm{x} \times \mathrm{x}$ love you $\mathrm{x}$ \\
\hline Impersonal & 2 & $\begin{array}{l}\text { Hi everyone, can you remember what time and place we are } \\
\text { having our next meeting? }\end{array}$ \\
\hline Elaborated nominal structure & 1 & Thank u very much u great woman.xxx \\
\hline Unsure & 3 & Hey bro. Found a hog roast that does gravey \\
\hline
\end{tabular}

By far the most frequent form was the use of people's full first names, which accounted for half the vocatives (50.9\%) when merged with first name familiarised (6) and first name + honorific (1). This is not necessarily surprising, given the attested role that first names can play in increasing rapport (Hultgren 2017). Nonetheless, it is interesting to note the frequent use of an address term that may seem particularly redundant in a context characterised by privacy, intimacy, and equal relations; and where addressees do not have to be discursively signalled.

In terms of the pragmatic functions apparently fulfilled with the use of vocatives (Table 3 ), we found that the overwhelming majority could be described as being involved in relational work (42, or $73.7 \%$ compared to $30 \%$ in CANCODE according to McCarthy and O'Keeffe, 2004: 8). We further categorised these into a number of subcategories which appeared to reflect the social functions typically carried out by mobile messaging (Thurlow and Brown 2003; Church and de Oliveira 2013). Only one of these (salutations) was unexpected, although probably idiosyncratic. The three salutations in Table 3 were written by the same texter (a male company director from China), directed at three different addressees, and so seemed to suggest a personal style, also involving the use of his name in a sign-off (Best wishes! N1).

Table 3. Distribution of vocative functions

\begin{tabular}{|c|c|c|}
\hline Function & No & Example \\
\hline \multicolumn{3}{|l|}{ Relational } \\
\hline - $\quad$ greeting & 21 & $\begin{array}{l}\text { Hi mate just got your message we cod have popped up } \\
\text { tonight, next week maybe? }\end{array}$ \\
\hline - thanking & 9 & Thanks $\underline{\text { hon }}$ see you tomorrow! Xx \\
\hline - $\quad$ heightening intimacy & 6 & 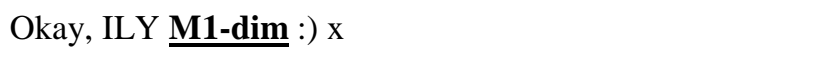 \\
\hline - $\quad$ salutation & 3 & $\begin{array}{l}\text { Dear } \underline{\mathbf{F 1}} \text {, How are you? Just to say I've got a meeting } \\
\text { tonight so I wont be around for tea tonight. Please do save } \\
\text { food for me. Best Wishes! N1 }\end{array}$ \\
\hline
\end{tabular}




\begin{tabular}{|c|c|c|}
\hline $\begin{array}{ll}- & \\
\text { - } & \text { evaluation } \\
\text { - } & \text { wishes }\end{array}$ & $\begin{array}{l}2 \\
1\end{array}$ & $\begin{array}{l}\text { It's long bro } \\
\text { Happy new year } \underline{\text { huni }} \text { xxxxx from F1-DIM ji x :p }\end{array}$ \\
\hline Focusing & 5 & $\begin{array}{l}\text { F1 have you seen the year } 2 \text { french modules? They look } \\
\text { fab! Xxx }\end{array}$ \\
\hline Mitigating & 7 & $\begin{array}{l}\text { Im sorry } \underline{\mathbf{F 1}} \text { i cant coming to wolverhampton.hope u have } \\
\text { lovely day xx }\end{array}$ \\
\hline Badinage & 6 & $\begin{array}{l}\text { Ah F1-DIM it must be the Irish in you. I bet it's been great } \\
\text { but you've been in lovely company - M1-DIM. X }\end{array}$ \\
\hline
\end{tabular}

Of these relational functions, greetings were the most frequent function involving vocatives ( $n=21$ ), no doubt in part because of the relatively high number of greetings across the corpus $(n=46)$. Most greetings were realised by first names $(n=13)$, in part because of the generally high frequency of this form. It is interesting to note that, despite the fact that greeting + name is structurally redundant in this context, interpersonal demands presumably encouraged people to frequently begin messages with this kind of greeting. These were often, but by no means always, used between colleagues.

6) Hi $\underline{\mathbf{F 1}} \times$ new 301 will start 1st July Monday eves 6-8:30

(female, learning and development coach, Cannock, 1969, to colleague)

7) Hi $\underline{\mathbf{F 1}}$ i have money 20 from my friend bought food.xxx

(male, decorator, Syria, 1977)

8) Hi M1-DIM, good, good. I'm fine thanks. Went out for a curry last night in Catshill, which was nice. Mumxx

(female, 1955, Stratford-on-Avon)

We also identified the use of vocatives in interpersonal acts of mitigation, as in:

9) $\quad$ F1-DIM just take some time to rest and chill. Things will feel a bit better then. Sometimes a bit of downtime is good for everyone to re focus

(female, learning support, Birmingham, 1992)

In this instance, it seems that a diminutive form as vocative is playing a role in softening the texter's advice that her friend should try to relax about the situation, given that negative 
politeness norms mean that suggesting an interlocutor alter their behaviour could be seen as an implicit criticism.

Also evident were examples of badinage, where in some cases the vocative appeared to function as a contextualisation cue that the following information should not be taken seriously, as in this comment on the high levels of time spent playing computer games, an interpretation that is confirmed in this case by the acronym 'lol':

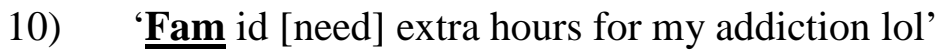
(male, student, London, 1994)

Thus, the categorisation points to the highly interpersonal role played by vocatives in mobile messaging.

Of particular interest, however, is the use of vocatives in a kind of summoning function which we call 'focusing'. These were instances in which the vocatives were used in messageinitial position in messages that initiated an exchange, seemingly with the intention of focusing the receiver's attention on the message that was to follow (as well as mitigating the demands placed on their interlocutor by receiving a message, as discussed below). This focusing function is particularly well illustrated in an exchange in which the sender uses message chunking whereby one utterances is broken up into more than one message (Baron 2008) - to isolate the focusing vocative from the message content:

\section{1) [first message] $\underline{\text { M1 }}$}

[second message] Sorry for being a pain, but are you actually annoyed with me?

(female, student, Birmingham, 1996)

In this instance, the user appears to be exploiting the ability to chunk messages in order to catch her interlocutor's attention in one message, while she writes her main message. Her first message serves as a kind of pre-text which prepares the interlocutor for the main text. In other cases, although the arrival of the message itself can be considered sufficient to 'summon' the receiver, it is clear that the vocative is being used similarly to prepare the receiver for the ensuing exchange. In these cases, the focuser appears to occur before the delivery of urgent news (12) or enquiries (13-15), all of which appear to demand or expect an immediate reply. 
Interestingly, although we cannot comment further on this, all examples are from women aged 19-30.

12) Bro it’s apparently Mother’s Day next week [emoji] someone at work has just told me! X

(female, paper conservator, Vietnam, 1985)

13) Babe did you get my message that I have your keys? Xxx

(female, administrator, Leeds, 1996)

14) F1 have you seen the year 2 french modules? They look fab! Xxx

(female, student, Surrey, 1996)

15) $\quad$ M2 what football team do you support so I can buy you a present to give you in may

(female, works with children, Birmingham, 1992)

These vocative usages also involve a degree of mitigation, although there is no obvious facethreatening act taking place beyond that which is caused by disturbing the receiver with the message (the distinction is not absolute but, in contrast, we classified Bro gimme some songs to download and Did you get my text lovely? as mitigators because of the bluntness of the bald imperative and the explicit request for a reply, respectively). Mobile messaging is generally considered to be less disruptive than, for example, a phone call, because users do not have to reply immediately (Darics 2014). However, in these cases, the urgency of the message - which would seem to demand a more prompt reply - appears to require some mitigation, which is fulfilled by the initial-position vocative. These vocatives, then, perform two pragmatic functions in drawing the reader's attention to the message whilst mitigating the potential disruption caused by its arrival. By identifying this vocative function, we show that some form of 'summoning' is sometimes necessary even in private one-to-one digital communication, whilst also highlighting the interpersonal considerations involved in summoning by mobile message, given people's apparent concern not to disturb others. In explaining the choice of vocative to fulfil this function, we can turn to Hultgren's (2017) study of call centre workers to similarly conclude that vocatives constitute easy, relatively invariant and very concise ways of fulfilling interpersonal functions; in this case, serving efficiently to both focus and mitigate, 
without the additional key presses or cognitive work that a more lengthy apology or explanation might involve.

In summary, in this section we have shown that vocatives - most frequently in the form of first names - are not only exploited as an interpersonal strategy in mobile messaging, but that even in this one-to-one private medium they are also involved in a summoning function, which involves focusing an interlocutor's attention on the message content as well as softening the demands made by the summons (in most cases, urgent requests for a response). This has implications both for our understanding of vocatives as being interpersonal and for the way in which interpersonal demands are handled via mobile messaging.

\section{Findings: position analysis}

In terms of the position of vocatives within the clause, we followed Leech (1999) in analysing the C-unit to which the vocative appeared most attached, adhering also to his guidelines that punctuation marks a C-unit boundary. The analysis reveals that the number of vocatives in initial position (all of which occurred at the start of the message) is in fact slightly higher than in spoken discourse. This is surprising, but perhaps gives some credence to the importance of the focusing function in mobile messaging. On the other hand, the fact that only one vocative occurred alone (as a focuser, see 11) is unsurprising. Finally, it is notable that a higher percentage of digital vocatives occur in mid-position than in speech. However, as evident in the examples, the difference between mid- and final-position is often a matter of punctuation and our decisions regarding what constituted the end of a C-unit (which included kisses).

Table 4. Vocative position in our corpus

\begin{tabular}{|c|c|c|c|}
\hline Position & Number & Comp. speech* & Example in mobile messaging \\
\hline Initial & $8(14 \%)$ & $11.5 \%$ & $\begin{array}{l}\text { Babe did you get my message that I have your keys? } \\
\mathrm{Xxx}\end{array}$ \\
\hline Mid-position & $15(26.3 \%)$ & $9.25 \%$ & $\begin{array}{l}\text { Hello F1-NICK by the mailbox getting off } \\
\text { mometarly I will head to library properly be in there } \\
\text { depending where you are upon arrival take it easy in } \\
\text { your own time <emoji > winkingface }</ \text { emoji }>\end{array}$ \\
\hline Final & $33(57.9 \%)$ & $68 \%$ & $\begin{array}{l}\text { That's ok } \underline{\mathbf{F 1}} \times \mathrm{x} \text { we all do it } \mathrm{x} \text { I was jelly before } \\
\text { mine } \mathrm{x}\end{array}$ \\
\hline Stand-alone & $1(1.8 \%)$ & $11.25 \%$ & M1 \\
\hline
\end{tabular}

*according to Leech (1999: 114-115) 


\section{Findings: vocatives as resources for identity positioning}

In this section, we look in more depth at two mobile exchanges to explore how vocatives are drawn upon in processes of discursive identity positioning alongside a range of other identity resources. The exchanges were chosen because in each case we had access to both sides of the conversation and because all interlocutors had been identified as frequent users of vocatives.

\subsection{Performing stylised gendered identity}

We spoke to two young men aged 18, LOB-37 and LOB-38, together. Both were born and live in Birmingham, although LOB-37 had also spent four years in Preston. Both speak English (and did so with us) and Urdu, but LOB-37 also claimed to speak some Spanish, while LOB38 a little Hindi and Punjabi and an ability to write (but not speak) Arabic. At the time of data collection, LOB-37 had an iPhone 6, and claimed to use SMS and WhatsApp frequently, while LOB-38 had an iPhone 5s and used SMS (including iMessage), as well as WhatsApp and Snapchat. We took screenshots of their digital interaction on LOB-37's phone $(n=4)$, but both men gave us consent to use their messages. We collected 13 messages from LOB-37 and 11 from LOB-38, making a total of 24 messages (91 words):

- 17 iMessages between LOB-37 (6 messages) and LOB-38 (11 messages)

- 7 iMessages from LOB-37 to another male friend

Figure 1. iMessage conversation between LOB-37 and LOB-38 

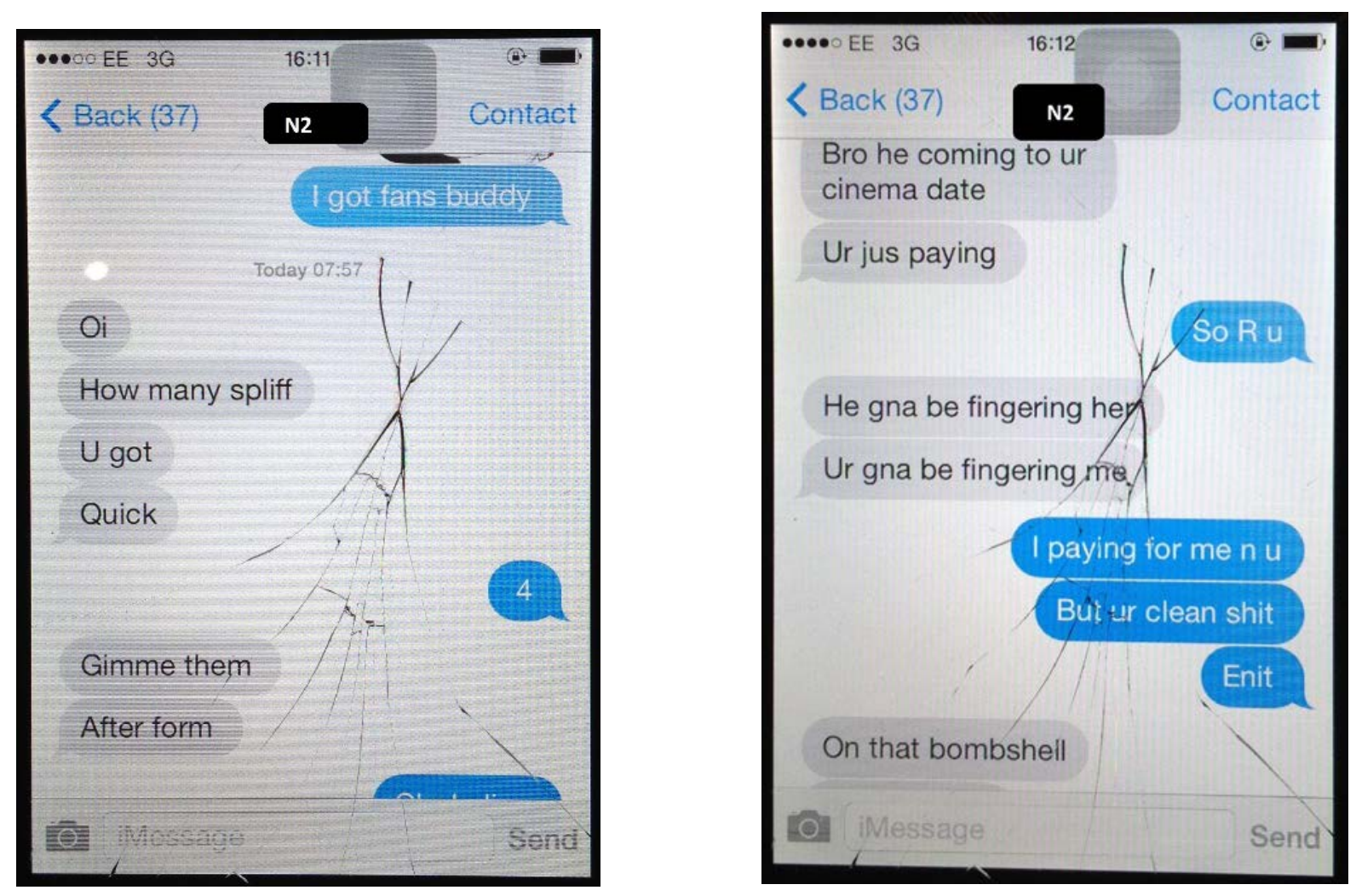

Figure 1 shows the 17 messages sent between the two interlocutors (with LOB-37's messages in blue on the right). Throughout their exchange the vocatives which the two men use are familiarisers, which usually occur between 'friends of equal status' (Murphy and Farr 2012: 2) and which, like dude, might be said to index cool camaraderie in certain contexts (Kiesling 2004). The specific forms used are buddy (by LOB-37, see Figure 1) and three instances of bro, used by both texters. By drawing on the wider use of buddy and bro elsewhere, we can surmise that the two texters project for themselves a relationship toward the other which is typified by friendly verbal sparring ('banter'), and an identity which is young and urban. There are two uses of these vocatives in the conversation between LOB-37 and LOB-38 are I got fans buddy and Bro he coming to ur cinema date, both of which we classified as badinage (see Figure 3). This is because of the nature of the surrounding discourse. Such classificational choices highlight the vital point that language is context based and accrues meaning through its cotext.

The vocatives are combined with other communicative resources to create what appears to be over-stylised, informal 'street language'. Androutsopoulos and Staehr (2018: 126), drawing on Madsen (2013), define street language as 'a peer register, which participants themselves associate with indexical values such as toughness, masculinity, youth, pan-ethnic minority street culture, and academic non-prestige'. In the exchange analysed here, street language is co-constructed through the use of abbreviations, colloquial respellings, slang terms, 
repetition, and short quick-fire turns. The vocatives described above play a role in the way the two young men position themselves and each other as users of this peer register.

Compared to other contributors to our corpus, the two men use a relatively high number of the aforementioned features. For example, between them, they use 26 respellings over 24 messages, which is more than one respelling per message (compared to 0.71 per message for men generally and 0.60 per message for women). Of these, 14 are letter homophones 7 are phonetically motivated respellings or contractions, and 3 involve consonant writing. As we report elsewhere, this can be seen as a 'male' way of respelling, in the sense that these respellings were preferred by men across our corpus (Tagg and Asprey 2017). The two men use three terms we categorised as slang: spliff (used by LOB-38), shit and enit (LOB-37). The two discourse markers they use (enit and like, both used by LOB-37) are informal, stigmatised, and respelt (enit is a respelling of innit, itself a contraction of the tag question isn't it). The two men use only one greeting (Oi, which is also informal, even impolite) and no sign-offs. The lack of sign offs and greetings suggests the men are treating their exchange as an ongoing conversation (Ito and Okabe 2005). Nor do they use full stops which, according to Gunraj et al. (2016), are often interpreted by young people as abrupt and as signalling the end of a digital conversation. The two young men also employ marked or non-standard grammatical forms which appeared to index a very casual style. These included:

- Omission of HAVE in “U got” (LOB-38)

- Omission of BE in “Bro he coming”, “He gna” (LOB-38) and “I paying” (LOB-37)

- Invariant plural (“How many spliff”) (LOB-37)

LOB-38's use of repetition - in the form of structural parallelism - as a communicative resource (Tannen 2007) further serves to position the two as engaging in playful and conversational banter. Structural parallelism is evident across the following turns: "He gna be fingering her" and "Ur gna be fingering me”, in which the transformation in pronoun (from $\mathrm{He}$ to $U$ ) in fact signals a change in meaning: while in the former fingering has a more literal sense of a man touching a woman's body, the latter use refers more metaphorically to the sender being expected to pay (the other objects "I paying for me $\mathrm{n} \mathrm{u}$ ”). The structural parallelism thus serves to link together these two actions in a meaningful way to emphasise that LOB-37's role on the 'cinema date' is purely a financial one. This point is colourfully made by LOB-38 as he exploits an affordance of the medium whereby messages can be sent in chunks and presented in parallel. 
In fact, both men chunk their turns in ways which have the effect of heightening the speech-like rhythm of their informal exchange. For example, LOB-38 divides one utterance into four chunks: Oi + How many spliff + U got + Quick, and LOB-37 into three: I paying for me $\mathrm{n} \mathrm{u}+$ But ur clean shit + Enit. Digital interactions performed through writing are not synchronous in the way that speech is, because interlocutors do not have access to each other's message production until the sender hits 'Send'; in this sense, they are only 'quasisynchronous' (Garcia and Jacobs 1998). However, chunking utterances as these young men do allows the receiver to process the message in ways which more closely resemble real-time, synchronous interaction. Although this is a widely-used practice reported elsewhere (Baron 2010), it seems to be exploited here for particular effects - to add to the construction of a clipped, rhythmic style and the feel of a spoken conversation, all of which feeds into the way in which they position themselves and each other through their mobile messaging.

\subsection{Performing femaleness}

UNI-3 and UNI-4 spoke to our two research assistants, Alice and Leonie, together. The two friends were female, both aged 19 at the time, and in their first year of university in Birmingham. UNI-3 is from a small town in Surrey, UK. She claims to speak and write both English and French well. At the time of data collection, she had a Google Nexus 4 phone, and claimed to frequently use SMS and Facebook Messenger. UNI-4 is from Leeds, and had also lived in Harrogate. She claims to speak and write English, French and Italian well. She had an Apple iPhone 5C and reported using SMS frequently, and WhatsApp and Facebook Messenger less frequently.

We collected 22 messages from UNI-3 and 21 from UNI-4, making a total of 43 messages (460 words). All the messages we collected were sent to the other, and are illustrated in the screen-snap of UNI-4's phone in Figure 2 (UNI-4's messages appear in blue on the right).

Figure 2. Facebook Messenger conversation between UNI-3 and UNI-4 


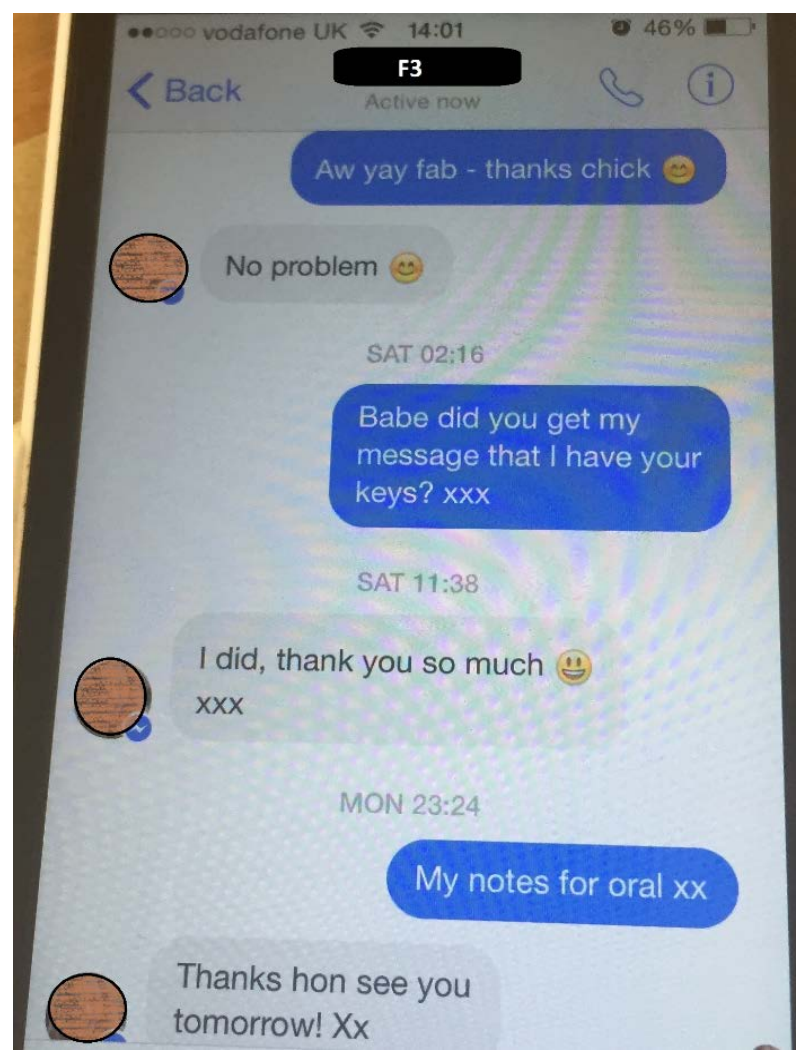

In their exchanges, the vocatives used are all endearments - chick, Babe, hon (Figure 2) and elsewhere lovely - vocative forms described by Biber et al. (1999: 1108) as indexing "the most familiar or intimate relationship”. So, they likely have connotations of intimacy and affection. In our analysis, these forms were categorised as involved in thanking ("thanks chick", and “Thanks hon”); and in focusing (“Babe did you get my message that I have your keys?”) as well as the mitigator (“Did you get my text lovely?”). In contrast to the young men, then, these young women are more overtly concerned with managing their relationship and their shared communication, rather than in acts of self-presentation and positioning.

Nonetheless, the choice of vocatives and other linguistic resources suggest that the women are choosing to present themselves in particular ways as they maintain their relationship. Firstly, as endearments such as chick, babe, hon and lovely probably index positive affect, the female texters we show here are happy to perform intimacy and affection to their friends. Interestingly, these vocatives have been critiqued on social media as overly feminine and cute. For example, the well-known social media site for mothers, Mumsnet, has a rivalry with parenting site Netmums. The latter have a minimal swearing policy and a tough line on content. Some users of Mumsnet characterise Netmums as 'Nethuns.' They position Netmums as a stereotypically feminine, two faced and saccharine web resource which is falsely overpositive 
to other women, with some posters overtly linking feminine vocative resources like hun to lower education:

The lesser spotted nethun can be identified through the use of:

Dreadful spelling/grammar/capitalisation

The words 'lol', 'hun' or 'hugz'

Text speak

Jeremy kyle type conundrums posted[...]

'Happy Mummy, Happy parenting' to justify parenting choices. ${ }^{2}$

The interpretation that our two participants are performing a kind of femininity through their messages is reinforced by the other resources on which the female texters draw and which work with the vocatives to create a particular communicative effect. In Figure 2, the interlocutors add two or three $x$ 's to four of the six messages, and smiling or grinning face emoji to three. UNI-4 uses the discourse marker and interjection "Aw yey”, and their exchange shows how both are careful to acknowledge each other's messages ("No problem”, "I did, thank you so much”). In our wider analysis of the corpus, we found that both kisses and emoji were more widely used by women than by men, suggesting a gendered use of these resources: men added kisses to their messages 18 times, and women 121; and men used 8 emojis while women used 74 (a substantial difference even taking into account the fact that women submitted around twice as many messages as men). In a digital medium such as this, interlocutors cannot rely on physical cues such as gesture, clothes, and actions with which to identify themselves, but must rely on textual cues. In this case, these come together to suggest a shared identity which emphasises femaleness. Although we do not suggest through these cases studies that all texters want to or will behave in the same way or deploy the same vocative resources, there are clearly parallels between the way in which the young male texters in the previous example indexed affection for each other and the way in which the females in this example do the same. The vocative resources they draw on differ, but the work is the same.

2 'zimm', 2011. “Am I being unreasonable to think the Nethuns are back?” $24^{\text {th }}$ November 2011. Mumsnet. [Online].

Available at: https://www.mumsnet.com/Talk/am_i_being_unreasonable/a1350019-Tothink-the-nethuns-are-back. Accessed on 25th April 2017. 


\section{Discussion and conclusion}

Our study contributes to the emerging field of internet pragmatics by investigating the impact of context on vocative use through analysis of a corpus of mobile messages. Although private one-to-one digital communication would not seem to require vocatives for summoning or turntaking, it would seem likely - due to the intimate nature of mobile messaging and the reliance on text-based cues - that texters may draw on vocatives for carrying out relational work. Our analysis revealed a similar range of vocative forms to those identified in speech, and that vocatives were used to carry out many of the interpersonal functions associated with mobile messaging such as greeting and thanking, as well as badinage. We also identified a more unexpected function, that of focusing, whereby the receiver's attention was drawn towards the message and the demand for a prompt reply was mitigated. In both this and the use of vocatives with greetings and salutations, it is interesting to note that texters are drawing on resources associated with other modes - informal conversation and, in the case of salutations like Dear F1, written letters - despite their apparent redundancy in this digital mode. This transfer of resources can also be seen in the use of spoken discourse markers such as $A w$, for example (Figure 2). Meanwhile, the fact that people feel obliged to mitigate their messages in some circumstances highlights their concern not to impose on interlocutors or to be seen to be demanding immediate replies. Thus, we can conclude - albeit on limited data - that vocatives may be used in the negotiation of communicative expectations around mobile messaging.

Our study also focused on the role that vocatives play in identity positioning. In text-based interactions via mobile messaging, it has been observed that identities must be performed primarily through graphological and linguistic resources. In this study, we explored how two young men use vocatives as part of a shared linguistic repertoire to co-construct a kind of 'street language' characterised by quick short turns, structural parallelism, and slang, as well as familiarising vocatives such as bro and buddy. By positioning themselves and each other in this way, they create a shared identity around which they can bond. In contrast, we also saw how two young women adopt very different vocative forms - endearments such as hon and babe - in order to perform more feminine identities. Whilst identity positioning is evident in a number of previous studies (e.g., Jaworski and Galasiński 2000), the focus has tended to be on the impact of vocatives on the relationship between interlocutors. By shifting the focus to the role of vocatives in identity performance, and on the positioning of others through the vocatives used to address them, we conceptualise the relationship between interlocutors not as static but as co-created and negotiated. 
Our analysis of the identity performances of these two dyads leads us to question the vocative form categorisation outlined by Biber et al. (1999), and particularly the distinction between familiarisers and endearments. Our analysis confirms our suspicion that the distinction has less to do with formal meaning, or with any difference in function, but is instead gendered: what Biber et al. (1999) label endearments are those vocatives which women tend to use, and those resources they label familiarisers, men.

Our study also serves to challenge the ongoing popular discourse surrounding the relative impoverishment of online communication, at least in comparison to the richness of spoken language, by detailing how users have access to, and exploit, vocatives as part of a range of interpersonal resources with which to fulfil interpersonal functions. We would suggest that other speakers might choose to use vocatives in less traditionally stratified ways, and that the findings of Kiesling (2004) about the vocative dude and its spread out from male-to-male use into female-to-female use and even to male-to-female use might be mirrored in the uses of our texters were a larger sample to be collected. We also suggest that this paper throws down theoretical challenges for those working at the interface of spoken language and internet pragmatics. Spoken models alone cannot account entirely for the ways in which texters behave, and written models of English seldom incorporate any vocative use. Fruitful areas for further research in internet pragmatics would be accounting for the patterns of vocative use we find in intimate and non-intimate text messages on a theoretical basis.

\section{References}

Androutsopoulos, Jannis, and Andreas Staehr. 2018. "Moving methods online: researching digital language practices.” In The Routledge Handbook of Language and Superdiversity, ed. by Angela Creese, and Adrian Blackledge, 118-132. Abingdon: Routledge.

Astruc-Aguilera, Lluisa. 2005. "The form and function of extra-sentential elements." Cambridge Occasional Papers in Linguistics 2: 1-25.

Bell, Allan. 1984. “Language style as audience design.” Language in Society 13(2): 145-204. boyd, danah, and Alice E. Marwick. 2011. "I tweet honestly, I tweet passionately: Twitter users, context collapse, and the imagined audience.” New Media \& Society 13(1): 114133.

Biber, Douglas, Stig Johansson, Geoffrey Leech, Susan Conrad, and Edward Finegan. 1999. Longman Grammar of Spoken and Written English. London: Longman.

Cameron. Deborah. 1995. Verbal Hygiene. London: Routledge. 
Church, Karen, and Rodrigo de Oliveira. 2013. "What's up with WhatsApp? Comparing mobile instant messaging behaviors with traditional SMS.” Proceedings of Mobile HCI2013: Collaboration and Communication. August 30th 2013, Munich, Germany, 352361. New York: ACM Publications.

Clark, Herbert H., and Thomas B. Carlson. 1982. “Hearers and Speech Acts.” Language 58(2): 332-373.

Darics, Erika. 2014. "The blurring boundaries between synchronicity and asynchronicity: New communicative situations in work-related instant messaging.” International Journal of Business Communication 51(4): 337-358.

Darics, Erika. 2016. “Digital media in workplace interactions.” In The Routledge Handbook of Language and Digital Communication, ed. by Alexandra Georgakopoulou, and Tereza Spilioti, 197-211. Abingdon: Routledge.

Davies, Bronwyn and Rom Harré. 1990. "Positioning: The discursive production of selves." Journal for the Theory of Social Behaviour 20(1): 43-63.

Eckert, Penny. 1995 “Gender and sociolinguistic variation.” In Language and Gender: A Reader, ed. by Jennifer Coates, 64-77. Oxford: Blackwell.

Frobenius, Maximiliane. 2014. 'Audience design in monologues: How vloggers involve their viewers.' Journal of Pragmatics 72: 59-72.

Georgakopoulou, Alexandra. 1997. "Self-presentation and interactional alliances in e-mail discourse: the style and code-switches of Greek messages.” International Journal of Applied Linguistics 7(2): 141-164.

Gillies, William. 1993. "Scottish Gaelic.” In The Celtic Languages, ed. by Martin Ball, 230304, London: Routledge.

Goffman, Erving. 1975. “Replies and responses.” Language in Society 5: 257-313.

Gunraj, Danielle N., April M. Drumm-Hewitt, Erica M. Dashow, Sri Siddhi N. Updadhyay, and Ceila M. Kin. 2016. “Texting insincerely: The role of the period in text messaging.” Computers in Human Behavior 55 (B): 1067-1075.

Hammond, Lila. 2005. Serbian: An Essential Grammar. London: Routledge.

Harré, Rom, and Luk Van Langenhove (eds.). 1999. Positioning Theory: Moral Contexts of Intentional Action. Oxford: Blackwell.

Herring, Susan E. 2007. “A faceted classification scheme for computer-mediated discourse.” Language@Internet 4, article 1. http://www.languageatinternet.org/articles/2007/761 (accessed 5 April 2017). 
Hill, Jane. 1995. "Mock Spanish: a site for the indexical reproduction of racism in American English.” Language and Culture: Symposium 2.

http://languageculture.binghamton.edu/symposia/2/part1/index.html (accessed 5 April 2017).

Hill, Jane. 1998. “Language, race, and white public space.” American Anthropologist 100(3): 680-689.

Holmes, Janet. 2008. Gendered Talk at Work: Constructing Gender Identity Through Workplace Discourse. Oxford: Blackwell.

Hultgren, Anna Kristina. 2017. "Vocatives as rationalized politeness: Theoretical insights from emerging norms in call centre service calls.” Journal of Sociolinguistics 21(1): 90-111.

Ito, Mizuko, and Daisuke Okabe. 2005. “Technosocial situations: Emergent structurings of mobile email use.” In Personal, Portable, Intimate: Mobile Phones in Japanese Life, ed. by Mizuko Ito, Daisuke Okabe, and Misa Matsuda, 257-276. Cambridge: MIT Press.

Jaworski, Adam, and Dariusz Galasiñski. 2000. "Vocative address forms and ideological legitimazation in political debates.” Discourse Studies 2(1): 35-53.

Katz, James E., and Mark Aakhus. 2002. Perpetual Contact: Mobile Communication, Private Talk, Public Performance. Cambridge: Cambridge University Press.

Kiesling, Scott. 2004. “Dude.” American Speech 79(3): 281-305.

Leppänen, Sirpa, Samu Kytölä, Henna Jousmäki, Saija Peuronen, S. and Elina Westinen. 2014. “Entextualisation and resemiotization as resources for identification in social media.” In The Language of Social Media: Identity and Community on the Iinternet, ed. by Philip Seargeant, and Caroline Tagg, 112-138. Basingstoke: Palgrave Macmillan.

Leppänen, Sirpa. Elina Westinen and Samu Kytölä (eds.). 2017. Social Media Discourse, (Dis)identifications and Diversities. Abingdon: Routledge.

Leech, Geoffrey. 1999. 'The distribution and function of vocatives in American and British English conversation.' In Out of Corpora: Studies in Honour of Stig Johansson, ed. by Hilde Hasselgård, and Signe Oksefjell, 107-120. Amsterdam: Rodopi.

Littlemore, Jeannette and Caroline Tagg. 2018. "Metonymy and text-messaging: a framework for understanding creative uses of metonymy.” Applied Linguistics 39(4): 481-507.

Lyons, Agnieszka. 2014. "Self-Presentation and self-positioning in text-messages: Embedded multimodality, deixis, and reference frame.” Unpublished $\mathrm{PhD}$ thesis, Queen Mary University of London.

Madianou, Mirca and Daniel Miller. 2012. Migration and New Media: Transnational Families and Polymedia. London: Routledge. 
McAdam, Noel. 2014. “Gregory Campbell banned in absentia over ‘curry my yoghurt' Irish language stunt.” Belfast Evening Telegraph, 5 November 2014.

http://www.belfasttelegraph.co.uk/news/politics/gregory-campbell-banned-in-absentiaover-curry-my-yoghurt-irish-language-stunt-30719543.html (accessed 5 April 2017).

Madsen, Lian Malai. 2013. "High and low in urban Danish speech styles.” Language in Society 42(2): 115-138.

Marwick, Alice E., and danah boyd. 2014. "Networked privacy: How teenagers negotiate context in social media.” New Media \& Society 16(7): 1051-1067.

McCarthy, Michael, and Anne O’ Keeffe. 2003. "What's in a Name? - Vocatives in casual conversations and radio phone-in calls.” In Corpus Analysis: Language Structure and Language Use, ed. by Pepi Leistyna, and Charles Meyer, 153-185. Amsterdan: Rodopi.

Murphy, Brona, and Fiona Farr. 2012. “'I’m fine girl, and how are you?’: The use of vocatives in spoken Irish English. In New Perspectives on Irish English, ed. by Bettina Migge, and Maíre Ní Chiosáin, 203-224. Amsterdam: John Benjamins.

O’Rahilly, Tomás. 1921. “The vocative in Modern Irish.” Ériu 9: 85-91.

Rainie, Lee, and Barry Wellman. 2012. Networked: The New Social Operating System. Cambridge, MA: MIT Press.

Sacks, Harvey, and Emanuel Schegloff. 1973. “Opening up closings.” Semiotica 8: 289-327.

Sadowska, Iwona. 2012. Polish: A Comprehensive Grammar. London: Routledge.

Schegloff, Emanuel. 1993. “Telephone conversation.” In The Encyclopedia of Language and Linguistics, ed. by R. E. Asher, and J. M.Y. Simpson, 4547-4549. Oxford: Pergamon Press.

Schegloff, Emanuel. 2002. "Beginnings in the telephone.” In Perpetual Contact: Mobile Communication, Private Talk, Public Performance ed. by James Katz, and Mark Aarhus, 284-300. Oxford: Pergamon Press.

Skovholt, Karianne. 2015. “Doing leadership in a virtual team: analysing addressing devices, requests, and emoticons in a leader’s e-mail messages.” In Digital Business Discourse ed. by Erika Darics, 101-121. Basingstoke: Palgrave Macmillan.

Tagg, Caroline. 2012. The Discourse of Text Messaging. London: Continuum.

Tagg, Caroline, and Esther Asprey. 2017. “Messaging in the Midlands: Exploring digital literacy repertoires in a superdiverse region.” IRiS Working Paper Series 16. http://www.birmingham.ac.uk/Documents/college-social-sciences/socialpolicy/iris/2017/IRiS-WP-16-2017.pdf. (accessed on 8 September 2017). 
Tagg, Caroline, and Philip Seargeant. 2014. “Audience design and language choice in the construction and maintenance of translocal communities on social network sites.” In The Language of Social Media: Identity and Community on the Internet, ed. by Philip Seargeant, and Caroline Tagg, 161-185. Basingstoke: Palgrave Macmillan.

Tannen, Deborah. 2007. Talking Voices: Repetition, Dialogue, and Imagery in Conversational Discourse ( $2^{\text {nd }}$ edn.). Cambridge: Cambridge University Press.

Thurlow, Crispin, and Alex Brown. 2003. "Generation Txt? Exposing the sociolinguistics of young people’s text-messaging.” Discourse Analysis Online 1(1).

https://extra.shu.ac.uk/daol/articles/v1/n1/a3/thurlow2002003.html (accessed 8 September 2017).

Wollaston, Sam. 2017. "How to send GIFs to your friends and groups on WhatsApp." Wired 25 March 2017. http://www.wired.co.uk/article/whatsapp-gifs-videos (accessed 18 September 2017).

Zappavigna, Michele. 2012. Discourse of Twitter and Social Media: How We Use Language to Create Affiliation on the Web. London: Continuum.

\section{Authors' addresses}

Esther Asprey

School of English

Curzon Building

Birmingham City University

Cardigan Street

Birmingham

B4 7AP

Esther.Pickersgill@bcu.ac.uk

Caroline Tagg

School of Languages and Applied Linguistics

Faculty of Wellbeing, Education and Language Studies

L1, Stuart Hall,

The Open University 
Milton Keynes MK7 6AA

caroline.tagg@open.ac.uk

\section{Biographical notes}

Esther Asprey is a Researcher in the School of English Research and Development Unit for English Studies, Birmingham City University. She has worked on a descriptive history of Birmingham and Black Country varieties, published by Edinburgh University Press. She has also written about identity and language change in the Birmingham region at a historical level, examining sound and syntactic change across time in the linguistic varieties of the region.

Caroline Tagg is Lecturer in the School of Languages and Applied Linguistics, Open University. Her research into language and digital technologies is predicated on the understanding that digital communication practices are embedded into individuals' wider social, political and economic lives. Her publications include The Discourse of Text Messaging (Continuum, 2012) and Taking Offence on Social Media: communication and conviviality on Facebook (with Philip Seargeant and Amy Aisha Brown, Palgrave, 2017). 